\title{
Addition of Aripiprazole to the Clozapine May Be Useful in Reducing Anxiety in Treatment-Resistant Schizophrenia
}

\author{
Aleksandar Chanachev, ${ }^{1}$ Nicolas Ansermot, ${ }^{2}$ Séverine Crettol Wavre, ${ }^{2}$ Ute Nowotka, ${ }^{1}$ \\ Maria-Eleni Stamatopoulou, ${ }^{3}$ Philippe Conus, ${ }^{1}$ and Chin B. Eap ${ }^{2}$ \\ ${ }^{1}$ Department of Psychiatry, Centre Hospitalier Universitaire Vaudois, Section Eugene Minkowski, Site de Cery, \\ 1008 Prilly, Switzerland \\ ${ }^{2}$ Unité de Biochimie et Psychopharmacologie Clinique, Centre de Neurosciences Psychiatriques, Site de Cery, \\ 1008 Prilly, Switzerland \\ ${ }^{3}$ Department of Psychiatry, Centre Hospitalier Universitaire Vaudois, Psychiatrie de Liason-Urgences et Crise, \\ 1011 Lausanne, Switzerland
}

Correspondence should be addressed to Aleksandar Chanachev, aleksandar.chanachev@chuv.ch

Received 23 June 2011; Accepted 11 July 2011

Academic Editors: J. S. Brar and Y. Kaneda

Copyright (C) 2011 Aleksandar Chanachev et al. This is an open access article distributed under the Creative Commons Attribution License, which permits unrestricted use, distribution, and reproduction in any medium, provided the original work is properly cited.

There exist many case reports and studies on the antipsychotic augmentation by aripirazole in partial responders to clozapine, the most seem to be finding a slight difference in the PANSS and CGI scores after the aripirazole addition. The results of our report are compatible with those of other studies but, we have found a considerable antianxiety action in both of the cases. The 5HT1A agonism of aripirazole could be hypothesized as mechanism contributing to this effect.

\section{Introduction}

Clozapine is the drug of choice in treatment-resistant schizophrenia, but $40-70 \%$ of clozapine-treated patients continue to demonstrate suboptimal clinical response [1-4].

Various augmentation strategies have been tested, including the use of other atypical antipsychotics, but no clear recommendations can presently be proposed [5-10].

Augmentation with aripiprazole has been documented in case reports [11], in open trials $[5,12]$, and in a randomized controlled study [13].

In this paper, we report on 2 cases in which augmentation with aripiprazole had a beneficial impact on anxiety.

\section{Case Presentation}

2.1. Case Report 1. Ms. A, a 40-year-old woman diagnosed with a residual schizophrenia [14] was admitted following an exacerbation of psychotic symptoms with a predominance of anxiety despite $700 \mathrm{mg} / \mathrm{d}$ of clozapine for two years. The clinical scores and the trough plasma concentrations of clozapine and norclozapine at admission were CGI :5; total PANSS: 123; positive: 17/49; negative: $18 / 49$; excited component: 12/35; general: 39/112; Hamilton-anxiety: 14/56; clozapine: $896 \mathrm{ng} / \mathrm{mL}$; norclozapine: $551 \mathrm{ng} / \mathrm{mL}$, respectively (clozapine therapeutic range: $350-600 \mathrm{ng} / \mathrm{mL}$ [15-17]). Because of the risks of seizures, the dose was reduced to $500 \mathrm{mg} / \mathrm{d}$, and aripiprazole $(10 \mathrm{mg} / \mathrm{d})$ was added. Clozapine and norclozapine plasma concentrations measured after 10 days were decreased according to the reduction of the dose $(615 \mathrm{ng} / \mathrm{mL}$ and $478 \mathrm{ng} / \mathrm{mL}$, resp.). The aripiprazole plasma concentration after 10 days was $282 \mathrm{ng} / \mathrm{mL}$. Following a clinical reduction of the anxiety, the patient was discharged from the hospital three weeks after the addition of aripiprazole.

A followup over 6 months did not reveal any change in the CGI and PANSS scores (at 6 months: CGI:5; total PANSS: 125 ; positive: $18 / 49$; negative: $23 / 49$; excited component 10/35; general: 38/112). On the other hand, the Hamilton-anxiety score diminished progressively to 12,7 , and 8 after one, three, and 6 months, respectively. Clozapine and norclozapine plasma levels were stable over this 
period (at the sixth month: $608 \mathrm{ng} / \mathrm{mL}, 443 \mathrm{ng} / \mathrm{mL}$, and $75 \mathrm{~kg}$, resp.), and the comedications (clorazepate $20 \mathrm{mg} / \mathrm{d}$, valsartane $40 \mathrm{mg} / \mathrm{d}$, zopiclone $7,5 \mathrm{mg} / \mathrm{d}$, and tamsulosine $0.4 \mathrm{mg} / \mathrm{d}$ ) were not modified. No reports are describing an impact on anxiety by the antihypertensive comedication by valsartane (an angiotensin II receptor antagonist) and tamsulosine (peripheral $\alpha 1$-antagonist). There is no significant pharmacokinetic or pharmacodynamic interactions of that comedication and the antipsychotic/anxiolytic treatments.

2.2. Case Report 2. Mr. L, a 48-year-old man with a diagnosis of residual schizophrenia [14] treated for many years with clozapine $500 \mathrm{mg} / \mathrm{d}$ was admitted because of the worsening of his anxiety. The clinical scores and the trough plasma concentrations of clozapine and norclozapine were: CGI : 4; total PANSS: 88; positive: 20/49; negative 25/49; excited component: 9/35; general 40/112. Hamilton-anxiety: 24/56; clozapine: $594 \mathrm{ng} / \mathrm{mL}$; norclozapine: $470 \mathrm{ng} / \mathrm{mL}$, respectively. Aripiprazole $10 \mathrm{mg} / \mathrm{d}$ was added to clozapine (dose unchanged) and lorazepam ( $1 \mathrm{mg} / \mathrm{d})$ was discontinued. The patient was discharged three weeks after the aripiprazole addition.

A followup over 3 months did not reveal any change in the CGI and PANSS scores (at 3 months: CGI : 4; total PANSS: 73; positive: 20/49; negative: 25/49; excited component: 7/35; general: 40/112), while the Hamilton-anxiety score diminished progressively to 19 and 15 after one and three months, respectively. The clozapine and norclozapine plasma concentrations at three months were $431 \mathrm{ng} / \mathrm{mL}$ and $343 \mathrm{ng} / \mathrm{mL}$, respectively.

\section{Discussion}

In the present paper the augmentation did not result in a reduction of psychotic symptoms despite a treatment period of 3 to 6 months, which is in agreement with previous reports $[5,10-13]$. Because a therapeutic window has been demonstrated for clozapine $[17,18]$, it is important to mention that therapeutic blood levels of clozapine were maintained during the whole observation period. An important reduction of anxiety was clinically observed in both cases, with a marked improvement of psychosocial functioning observed, which allowed a change of residential institution of both cases, three and six months after the discharge from the hospital, for a residential stay in more open environment with less psychosocial accompanying measures.

It has been suggested that in anxiety disorders, the adjunction of atypical antipsychotics to the current SSRI and/or benzodiazepine treatment could, through the modulation of the dopaminergic system, be beneficial but the data are not conclusive $[19,20]$.

The agonist action of aripiprazole on the 5HT1A receptors could eventually contribute to the antianxiety action that we have observed [21].

However, considering the present observations could be due to external factors or to the natural evolution of the illness, a randomized controlled study is required to evaluate the efficacy of the clozapine-aripiprazole combination in cases of treatment-resistant schizophrenia with predominance of anxiety. Moreover, the anxiety observed in Case 1 could have been in part attributable to psychotoxic effects due to the high plasma concentration at the begining of the followup [22].

\section{Disclosure}

The authors attest that their research is not sponsored by any pharmaceutical companies, biomedical device manufacturers, or other corporation whose products or services may be related to the subject matter of the article and that they have no a financial relationship with this kind of commercial organizations.

\section{Acknowledgments}

P. Conus received an unrestricted educational grant for an investigator initiated trial from Bristol-Myers Squibb, and supports for attending conferences and/or giving speeches from Bristol-Myers Squibb, Janssen-Cilag, Eli Lily and Astra Zeneca. C. B. Eap received non-restricted educational grants for investigator initiated trials from Janssen-Cilag and Bristol-Myers Squibb. He received honoraria for conferences or teaching CME courses from Astra Zeneca, Bristol-Myers Squibb, Eli Lily, Essex Chemie, Glaxo-Smith Kline, JanssenCilag, Lundbeck, Novo Nordisk, and Organon.

\section{References}

[1] J. Kane, G. Honigfeld, J. Singer, and H. Meltzer, "Clozapine for the treatment-resistant schizophrenic. A double-blind comparison with chlorpromazine," Archives of General Psychiatry, vol. 45, no. 9, pp. 789-796, 1988.

[2] A. Cipriani, M. Boso, and C. Barbui, "Clozapine combined with different antipsychotic drugs for treatment resistant schizophrenia," Cochrane Database of Systematic Reviews, no. 3, Article ID CD006324, 2009.

[3] R. R. Conley and D. L. Kelly, "Management of treatment resistance in schizophrenia," Biological Psychiatry, vol. 50, no. 11, pp. 898-911, 2001.

[4] J. A. Lieberman, A. Z. Safferman, S. Pollack et al., "Clinical effects of clozapine in chronic schizophrenia: response to treatment and predictors of outcome," American Journal of Psychiatry, vol. 151, no. 12, pp. 1744-1752, 1994.

[5] C. I. Mitsonis, N. P. Dimopoulos, P. A. Mitropoulos et al., "Aripiprazole augmentation in the management of residual symptoms in clozapine-treated outpatients with chronic schizophrenia: an open-label pilot study," Progress in NeuroPsychopharmacology and Biological Psychiatry, vol. 31, no. 2, pp. 373-377, 2007.

[6] F. Mouaffak, C. Tranulis, R. Gourevitch et al., "Augmentation strategies of clozapine with antipsychotics in the treatment of ultraresistant schizophrenia," Clinical Neuropharmacology, vol. 29, no. 1, pp. 28-33, 2006.

[7] R. C. Josiassen, A. Joseph, E. Kohegyi et al., "Clozapine augmented with risperidone in the treatment of schizophrenia: a randomized, double-blind, placebo-controlled trial," American Journal of Psychiatry, vol. 162, no. 1, pp. 130-136, 2005. 
[8] A. E. Anil Yagcioglu, B. B. Kivircik Akdede, T. I. Turgut et al., "A double-blind controlled study of adjunctive treatment with risperidone in schizophrenic patients partially responsive to clozapine: efficacy and safety," The Journal of clinical psychiatry, vol. 66, no. 1, pp. 63-72, 2005.

[9] W. G. Honer, A. E. Thornton, E. Y. H. Chen et al., "Clozapine alone versus clozapine and risperidone with refractory schizophrenia," New England Journal of Medicine, vol. 354, no. 5, pp. 472-482, 2006.

[10] G. Remington, "Augmenting clozapine response in treatmentresistant schizophrenia," in Therapy-Resistant Schizophrenia, H. Elkis and H. Y. Meltzer, Eds., vol. 26 of Advances in Biological Psychiatry, pp. 129-151, Karger, Basel, Switzerland, 2010.

[11] K. Karunakaran, T. E. Tungaraza, and G. C. Harborne, "Is clozapine-aripiprazole combination a useful regime in the management of treatment-resistant schizophrenia?" Journal of Psychopharmacology, vol. 21, no. 4, pp. 453-456, 2007.

[12] D. C. Henderson, L. Kunkel, D. Nguyen et al., "An exploratory open-label trial of aripiprazole as an adjuvant to clozapine therapy in chronic schizophrenia," Acta Psychiatrica Scandinavica, vol. 113, no. 2, pp. 142-147, 2006.

[13] J. S. Chang, Y. M. Ahn, H. J. Park et al., "Aripiprazole augmentation in clozapine-treated patients with refractory schizophrenia: an 8-week, randomized, double-blind, placebo-controlled trial," Journal of Clinical Psychiatry, vol. 69, no. 5, pp. 720-731, 2008.

[14] American Psychiatric Association, Diagnostic and Statistical Manual of Mental Disorders DSM-IV-TR, American Psychiatric Publishing, 4th edition, 2000.

[15] W. Guy et al., ECDEU Assessment Manual for Psychopharmacology, U.S. Department of Helath, Education, and Welfare, Rockville, Md, USA, 1976.

[16] S. R. Kay, L. A. Opler, and A. Fiszbein, Positive and Negative Syndrome Scale-Manual, Multi-Health Systems, New York, NY, USA, 1992.

[17] P. Baumann, C. Hiemke, S. Ulrich et al., "The AGNPTDM expert group consensus guidelines: therapeutic Drug Monitoring in psychiatry," Pharmacopsychiatry, vol. 37, no. 6, pp. 243-265, 2004.

[18] P. J. Perry, D. D. Miller, S. V. Arndt, and R. J. Cadoret, "Clozapine and norclozapine plasma concentrations and clinical response of treatment-refractory schizophrenic patients," American Journal of Psychiatry, vol. 148, no. 2, pp. 231-235, 1991.

[19] K. Gao, D. Muzina, P. Gajwani, and J. R. Calabrese, "Efficacy of typical and atypical antipsychotics for primary and comorbid anxiety symptoms or disorders: a review," Journal of Clinical Psychiatry, vol. 67, no. 9, pp. 1327-1340, 2006.

[20] R. A. Lorenz, C. W. Jackson, and M. Saitz, "Adjunctive use of atypical antipsychotics for treatment-resistant generalized anxiety disorder," Pharmacotherapy, vol. 30, no. 9, pp. $942-$ 951, 2010.

[21] M. A. Katzman, "Aripiprazole: a clinical review of its use for the treatment of anxiety disorders and anxiety as a comorbidity in mental illness," Journal of Affective Disorders, vol. 128, supplement 1, pp. S11-S20, 2011.

[22] S. Pallanti, L. Quercioli, and A. Pazzagli, "Social anxiety and premorbid personality disorders in paranoid schizophrenic patients treated with clozapine," CNS Spectrums, vol. 5, no. 9, pp. 29-43, 2000. 


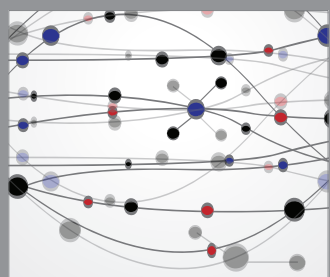

The Scientific World Journal
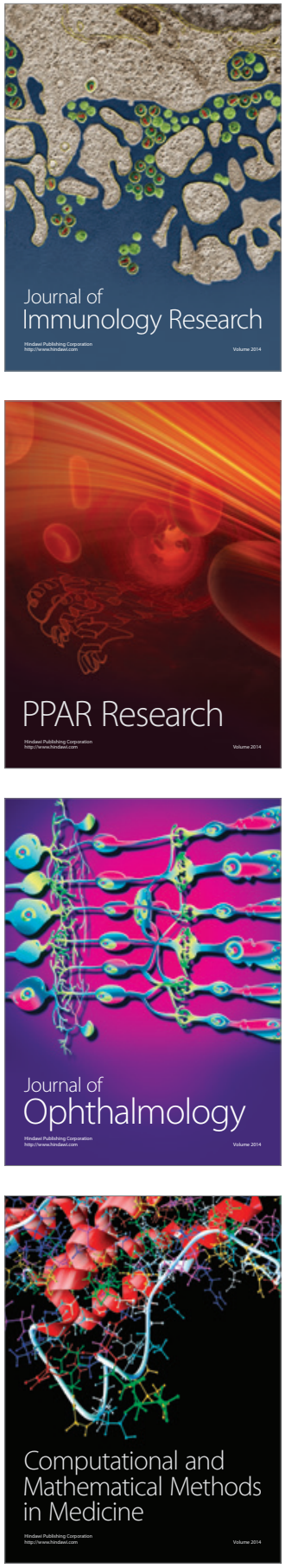

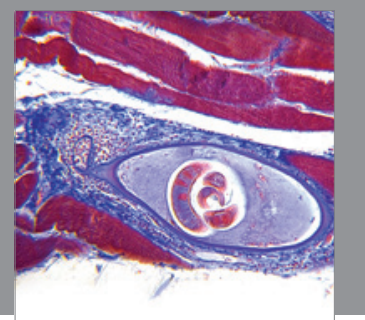

Gastroenterology

Research and Practice
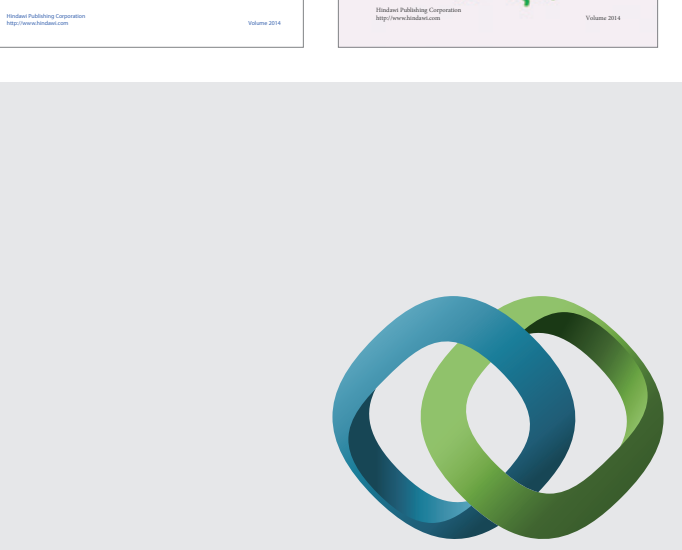

\section{Hindawi}

Submit your manuscripts at

http://www.hindawi.com
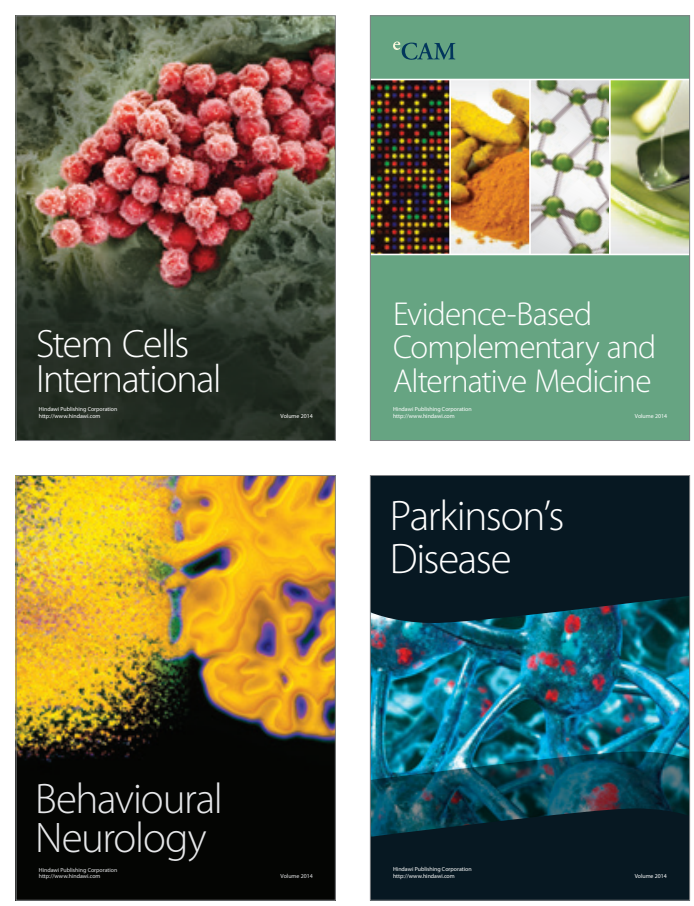

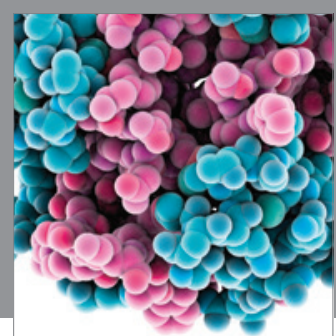

Journal of
Diabetes Research

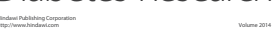

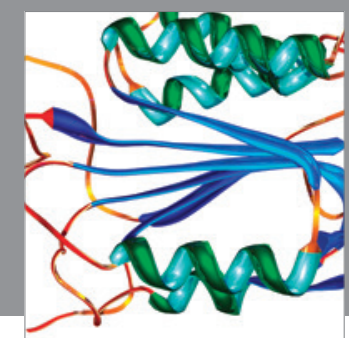

Disease Markers
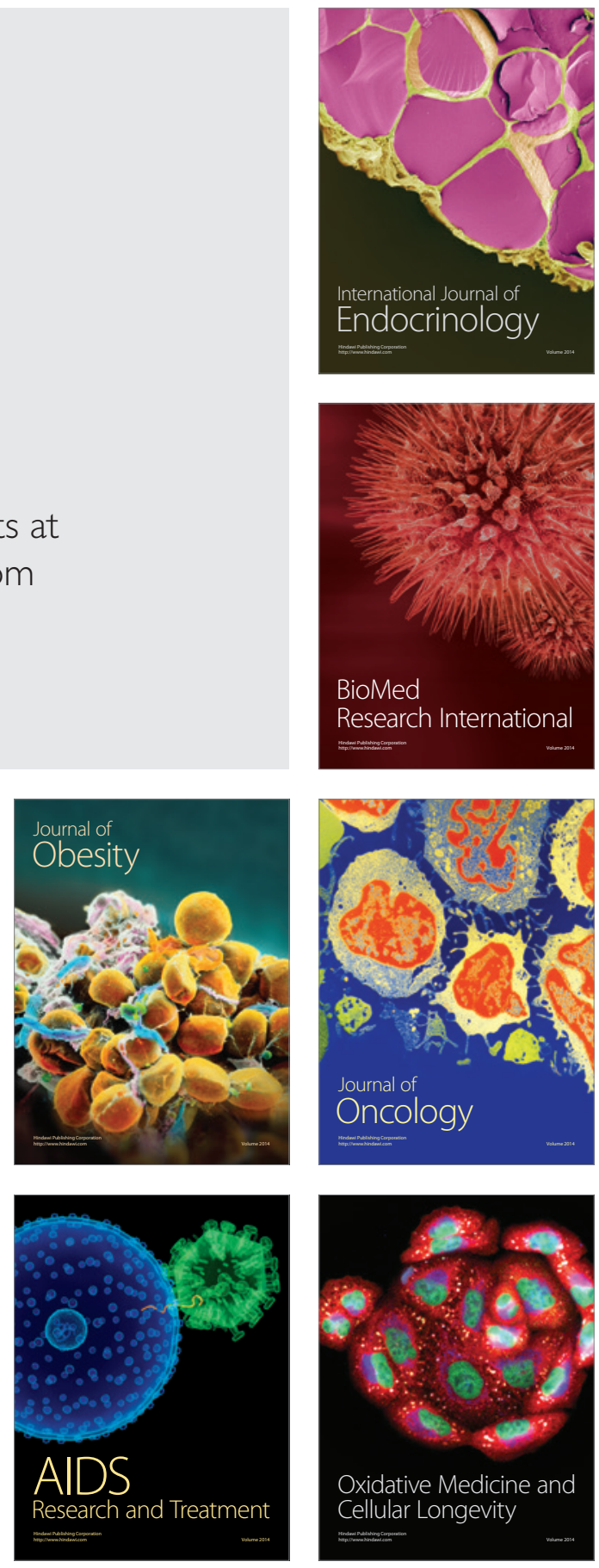